\title{
Statistical Verification of Numerical Weather Prediction (NWP) for Rainfall Estimation in the East Coast Region
}

\author{
Aisar Ashra M. Ashri ${ }^{1}$ *, Wardah Tahir ${ }^{1}$, Nurul Syahira M. Harmay ${ }^{1}$, Intan Shafeenar A. Mohtar ${ }^{1}$, Sazali Osman $^{2}$, \\ Wan Hazdy Azad Wan Abdul Majid ${ }^{2}$
}

\author{
${ }^{I}$ Faculty of Civil Engineering, Universiti Teknologi MARA, Shah Alam, Selangor, Malaysia \\ ${ }^{2}$ Flood Forecasting and Warning Centre, Department of Irrigation and Drainage, Malaysia \\ *Corresponding author E-mail: aisarashra@yahoo.com
}

\begin{abstract}
Intense hydrological event such as floods are increasing lately especially in Peninsular Malaysia. Therefore, it is important to forecast the intense rainfall as part of flood preparedness and mitigation measures. In this study, Numerical Weather Prediction (NWP) model precipitation outputs using Weather Research and Forecasting (WRF) with horizontal resolution of $3 \mathrm{~km}$ have been validated against observed rainfall data measurements for its performance measurement. Forecasted rainfall event data of three (3) states in the East Coast Region; Kelantan, Terengganu and Pahang were evaluated and compared with the observed rainfall data before statistically verifying their accuracy using False Alarm Ratio (FAR) and Probability of Detection (POD). The results indicate a very promising potential of the models in producing quantitative precipitation forecast (QPF) for flood forecasting purpose in Kelantan, Terengganu and Pahang. Since these three states, which are located in the East Coast region of Peninsular Malaysia experienced annual flood event, accurate forecast rainfall data can be used to improve forecast information for flood indicator.
\end{abstract}

Keywords: Numerical Weather Prediction (NWP); Peninsular Malaysia; Quantitative precipitation forecast (QPF); Rainfall; WRF Model.

\section{Introduction}

Numerical Weather Prediction (NWP) is the most recent weather prediction technique that is available worldwide. The advanced technology in computing techniques and data assimilation has increased the use of NWP models as a tool for flood forecasting. Numerical weather models such as WRF estimate the state of the near-future atmosphere by solving atmosphere dynamic and thermodynamic equations, based on initial conditions. [1]. The WRF model is one of the most advanced mesoscale NWP model, designed in collaborative partnership, principally among the National Centre for Atmospheric Research (NCAR) and the National Oceanic and Atmospheric Administration. WRF is suitable for research and operational forecasting. [2].

Many studies had indicated the ability of WRF to provide a better forecast. $[3,4,5,6,7]$. There are many forecasts outputs from the WRF model such as rainfall, humidity, wind speed and a range of other derived variables, which may be useful for flood forecasting. These sequences can be used as input to rainfall- runoff model for flood prediction and could also be used in integrated system like WRF-Hydro. [8, 9].

Rainfall prediction using NWP models like Fifth Generation Mesoscale Model (MM5) or Weather Research and Forecast model (WRF) had been introduced in Malaysia by Malaysian Meteorological Department (MMD). MMD used NWP namely Weather Research and Forecasting (WRF) model to estimate the weather forecasting throughout the country. The working mechanism of WRF used by MMD can be referred to Fig. 1. Initial data in a specified format is provided into the model as an External Data sources. These data are formatted by OBSGRID and WPS system as a pre-processing system. Generated results from WPS system are then provided into the model processing system. Finally, analyzed model outputs are represented by different post-processing tools which are provided with the model installation.

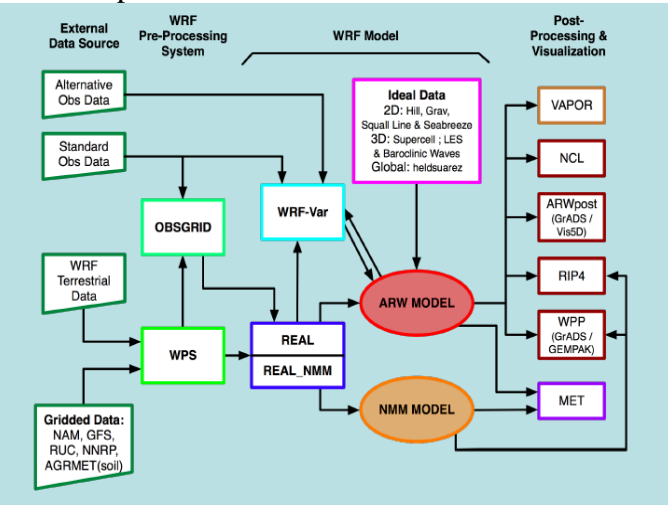

Fig.1: Weather Research and Forecasting model system overview [10]

Reliable forecast of intense rainfall episodes is extremely challenging and can play significant role in flood warning and disaster management. The accuracy of the model is extremely important in rainfall forecasting estimation in order to reduce the flood risk and other physical characteristics of flood. [11]. Previous study conducted by [12] using statistical verification method in comparing the forecast rainfall data of two NWP model namely Fifth Generation Penn State/NCAR Mesoscale (MM5) and WRF with the observed rainfall data in Kelantan indicates that the models able to perform for low and moderate rainfall but it is not the case for heavy rainfall. However, the case study only focuses in Kelantan 
River Basin and the accuracy of performance are not being compared within the other states around Kelantan region.

The objectives of this study are to assess the performance measurement of rainfall forecasting from WRF model by comparison analysis with observed rainfall; to determine the performance measurement of rainfall forecast data from Numerical Weather Prediction (NWP) WRF model using POD and FAR and compare the performance of WRF model between three states in the East Coast region of Peninsular Malaysia. Accurate forecast rainfall data then can be used to improve forecast information for flood indicator.

\section{Method}

Three (3) states (as shown in Fig.2) in the East Coast region of Peninsular Malaysia are selected as the study area. The rainfall forecasting data using NWP WRF model are determined from the MMD while the observed rainfall data are obtained from the Department of Irrigation and Drainage (DID). Ten rainfall stations from each state in the East Coast region; Kelantan (10), Terengganu (10) and Pahang (10) are selected based on the stations that have complete rainfall data during August 2016. The latitude and longitude for each selected rainfall stations in Kelantan, Terengganu and Pahang are then being determined in order to complete the analysis for forecast rainfall data and observed data. Selected rain gauge stations are shown in Table 1 to Table 3.

Firstly, the rainfall forecast data produced from WRF model are compared with the observed data by using comparison analysis. By comparison analysis, the patterns and trends of the both data can be determined and evaluated. The accumulated rainfall data from UTC 12 at $10^{\text {th }}$ August 2016 until $15^{\text {th }}$ August 2016 which are equivalent to 120 hours or 5 days are obtained. After the comparison analysis, the accuracy of forecast and observed rainfall data are statistically verified by using Probability of Detection (POD) and False Alarm Ratio (FAR). The mean hourly forecast and observed rainfall data for each state are calculated and then the statistical verification analysis is being done. The perfect score for POD is 1 while the perfect score for FAR is 0 . These statistical verification data are then being used to compare the performance of WRF model between three (3) states in the East Coast region of Peninsular Malaysia to determine which state gives the best performance accuracy between forecast and observed rainfall data. Fig. 3 illustrate the work stages adopted in this study.

Table 1: Location of selected raingauge stations in Kelantan

\begin{tabular}{|l|l|l|}
\hline Station & Latitude & Longitude \\
\hline 4614002 Lojing & 4.60000 & 101.4000 \\
\hline 4720026 LadangMentara & 4.45200 & 102.0100 \\
\hline 4819027 GuaMusang & 4.87917 & 101.9694 \\
\hline 5120025 Balai Polis Bertam & 5.08450 & 102.0255 \\
\hline 5322044 Kg Lalok & 5.30830 & 102.2750 \\
\hline 5520001 UluSekor & 5.33500 & 102.0030 \\
\hline 5522047 JPS Kuala Krai & 5.31550 & 102.1210 \\
\hline 5718001 Kg Gemang Bahru & 5.45400 & 101.5200 \\
\hline 5723056 Telusan & 5.45300 & 102.1920 \\
\hline 5823001 Ibu Bkln Tiga Daerah & 5.51500 & 102.2040 \\
\hline
\end{tabular}

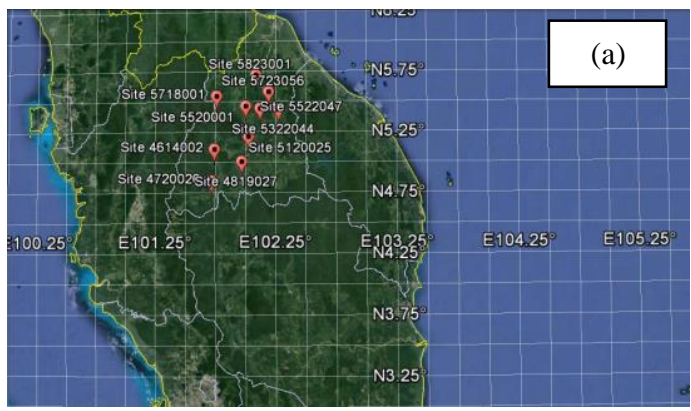

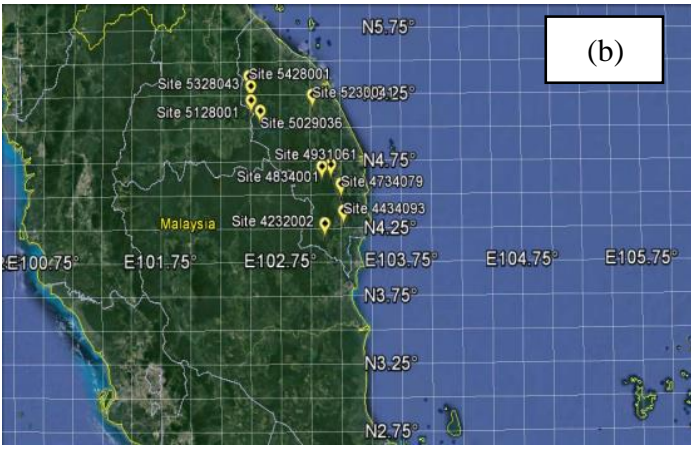

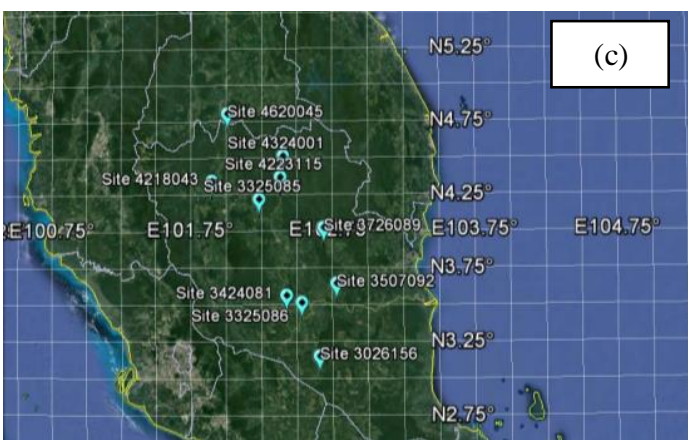

Fig.2: Map of Malaysia showing the East Coast region which are a) $\mathrm{Ke}$ lantan b) Terengganu and c) Pahang (Source: Google Maps, 2017)

Table 2: Location of selected raingauge stations in Terengganu

\begin{tabular}{|l|l|l|}
\hline Station & Latitude & Longitude \\
\hline 4232002 Jambatan Air Puteh & 4.16150 & 103.11550 \\
\hline 4434093 Sek Keb Temasek & 4.25400 & 103.2705 \\
\hline 4734079 Sek Men Sultan Omar & 4.45450 & 103.2510 \\
\hline 4834001 K. Bidan Kuala Abang & 4.49400 & 103.2500 \\
\hline 4931061 Ldg Koko Jerangau & 4.58400 & 103.0930 \\
\hline 5029036 Rmh Pam Paya Kemat & 5.00300 & 102.5810 \\
\hline 5128001 Sg Gawi & 5.08350 & 102.5040 \\
\hline 5230041 S.K Kuala Telemong & 5.12100 & 103.0155 \\
\hline 5328043 Kg Bukit Berangan & 5.19000 & 102.5020 \\
\hline 5428001 Kg Batu Hampar & 5.26500 & 102.4855 \\
\hline
\end{tabular}

Table 3: Location of selected raingauge stations in Pahang

\begin{tabular}{|l|l|l|}
\hline Station & Latitude & Longitude \\
\hline 3726089 JKR Jempol & 3.72778 & 102.6444 \\
\hline 3325086 Kg Kuala Bera & 3.39028 & 102.5333 \\
\hline 3325085 Kg Batu Che Mek & 3.32778 & 102.5069 \\
\hline 3424081 JPS Temerloh & 3.43889 & 102.4264 \\
\hline 3026156 Pos Iskandar & 3.02778 & 102.6583 \\
\hline 4223115 Kg Merting & 4.24306 & 102.3833 \\
\hline 4324001 Kuala Tahan & 4.38611 & 102.4028 \\
\hline 4218043 Paya Tepuai & 4.21667 & 101.9000 \\
\hline 4620045 Paya Laloh & 4.67778 & 102.0083 \\
\hline 3527092 Lubok Paku & 3.51944 & 102.7778 \\
\hline
\end{tabular}




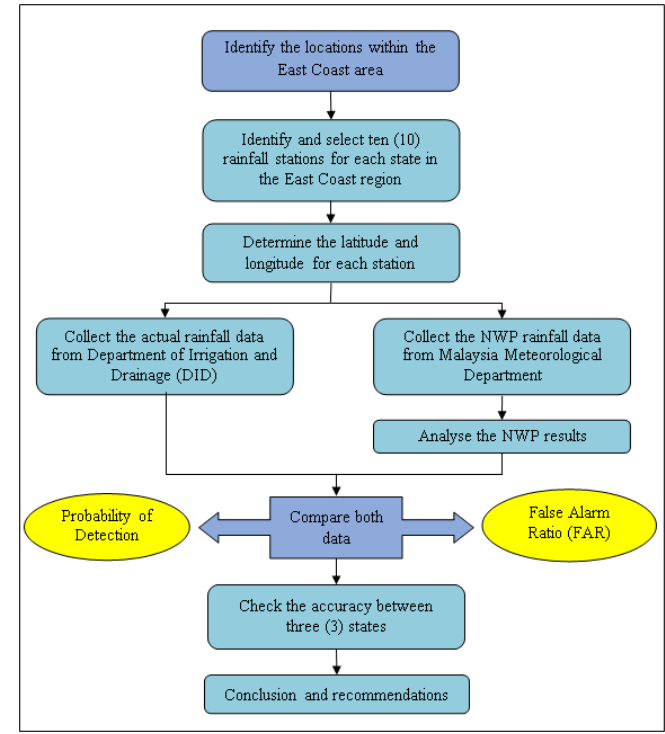

Fig.3: Research methodology be adopted for this study

\section{Results And Discussion}

The hourly forecast rainfall data starting from UTC 12 on $10^{\text {th }}$ August 2016 until $15^{\text {th }}$ August 2016 have been obtained from the Malaysia Meteorological Department (MMD). Total forecast and observed rainfall data from each station in Kelantan, Terengganu and Pahang are shown in Fig. 4. Fig. 5(a) shows the mean hourly rainfall events in Kelantan for 120-hours durations for overall 10 stations. Though the forecast model shows an overestimate forecasting events for example during $69^{\text {th }}$ hour $(4.75 \mathrm{~mm} / \mathrm{h})$ mean hourly rainfall, the forecast and observed rainfall data indicate similar pattern. From $10^{\text {th }}$ August to $15^{\text {th }}$ August 2016, Kelantan experienced highest mean hourly rainfall events during $21^{\text {st }}$ hour $(3.5 \mathrm{~mm} / \mathrm{h})$ and then it fluctuates until $71^{\text {st }}$ hour before having non-rainfall events until hour 120 .

The rainfall pattern between forecast and observed data in Terengganu also shows encouraging result as shown in Fig. 5(b). The WRF model able to obtain the pattern even though it did not able to forecast correctly. For example, the highest mean hourly rainfall event occurs at $49^{\text {th }}$ hour $(6.75 \mathrm{~mm} / \mathrm{h})$ but the model forecast zero rainfall occurrence and this is vice versa to the non-event occurrence during $2^{\text {nd }}$ to $15^{\text {th }}$ hour. Fig. 5(c) shows the mean hourly rainfall events in Pahang. There are two times where the heavy rainfall is less than $3 \mathrm{~mm} / \mathrm{h}$ occurs which during the $1^{\text {st }}$ hour and $27^{\text {th }}$ hour. Both time gives almost the same rainfall event, which is around $2.5 \mathrm{~mm} / \mathrm{h}$. As a result, for the Pahang state, the WRF model did not correctly forecast the rainfall event and pattern during these two hours. The forecast model was not satisfactorily performing during heavy rainfall event for Pahang state.

Two statistical verification method are used which are POD and FAR to compare the performance of WRF model between three states in the East Coast region of Peninsular Malaysia. The POD and FAR results analysis for each state in the East Coast region are shown in Fig. 6. For POD analysis in Kelantan, the ratio is about 0.4545 while 0.2188 for FAR analysis which is almost 0 . In Terengganu, the POD value indicates higher event that are correctly forecasted with ratio of 0.5870 . Meanwhile, the FAR analysis in Pahang shows highest ratio which is 0.6800 that indicates high probability of false detection. The performance of WRF model in Kelantan is the most satisfying compared to Terengganu and $\mathrm{Pa}-$ hang. Kelantan shows the most significant ratio for both value of POD and FAR. However, none of the three states give the good score for both statistical verification analyses.

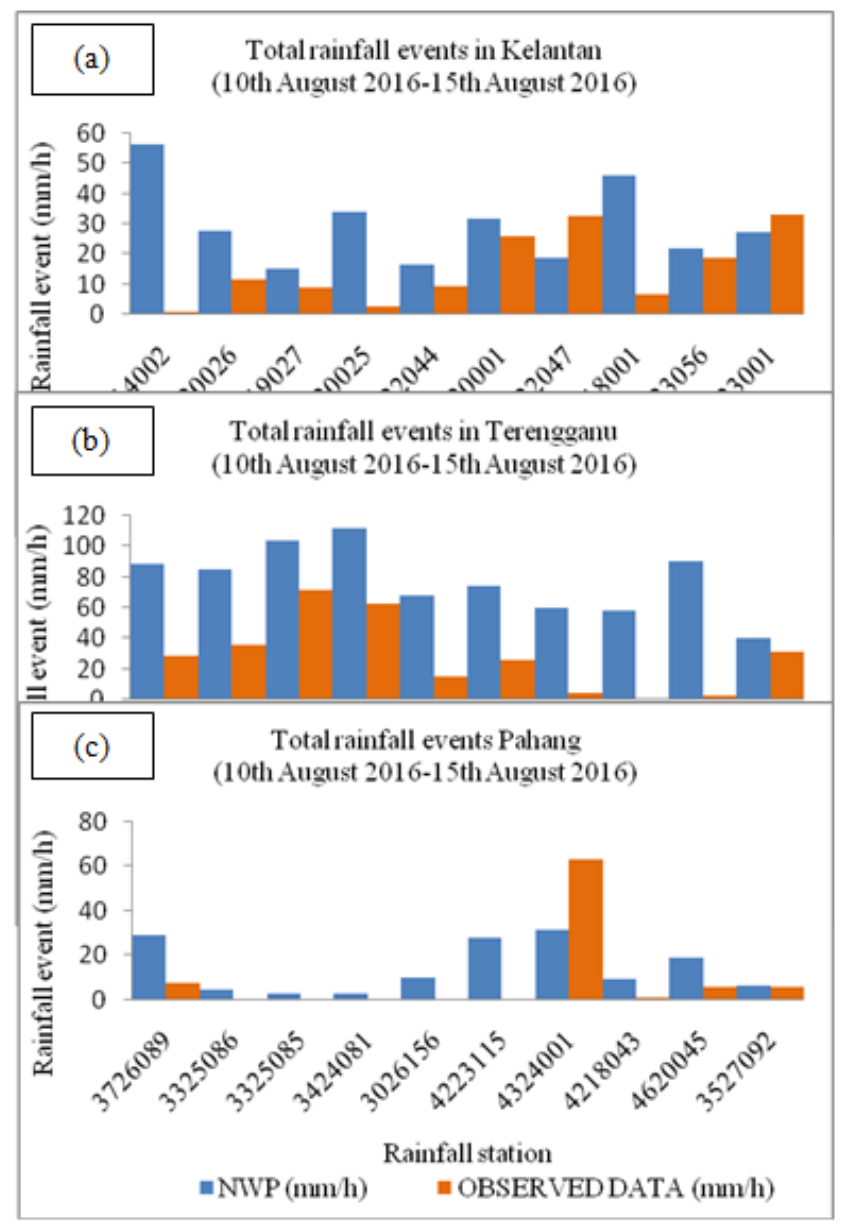

Fig. 4: Total rainfall events in (a) Kelantan (b) Terengganu and (c) Pahang for five days
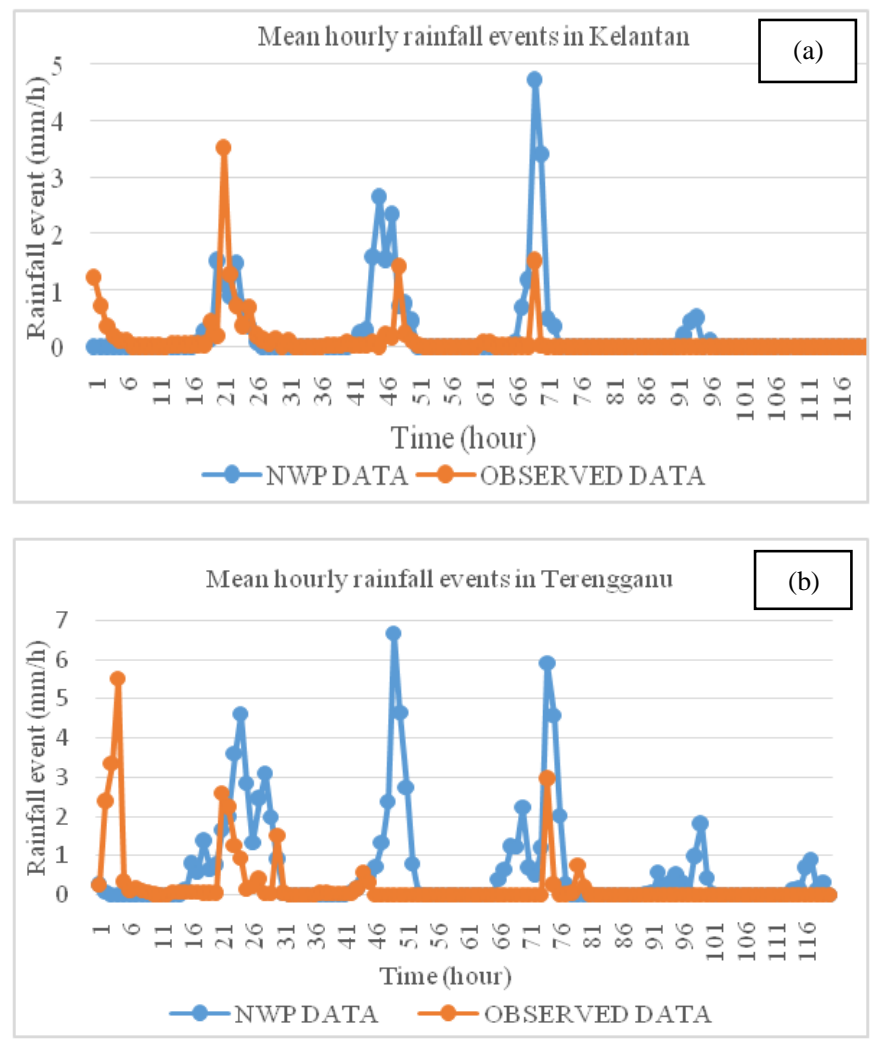


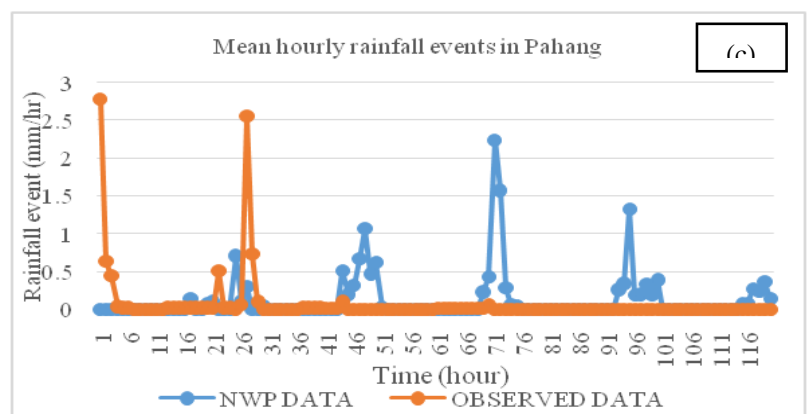

Fig. 5: Mean hourly rainfall events in (a) Kelantan (b) Terengganu and (c) Pahang

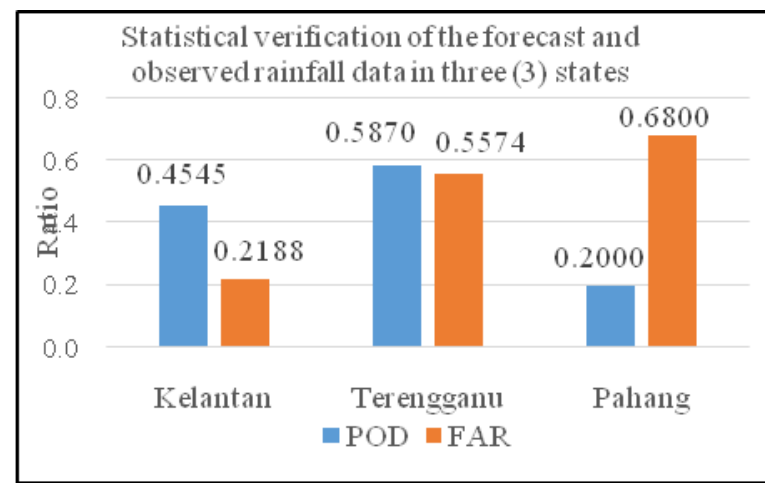

Fig. 6: Comparison of POD and FAR for Kelantan, Terengganu and Pahang

\section{Conclusion}

The mean hourly of each state for both forecast and observed data are evaluated before statistical verification process are being done. Kelantan shows the best pattern of forecast and observed rainfall data compared to the other state. The POD and FAR analysis of mean hourly rainfall data for each state are used to verify the rainfall accuracy between forecast and observed data. The statistical verification analysis also indicate that Kelantan has the best ratio compared to Terengganu and Pahang. Though the WRF model have performed quite satisfactorily in certain cases during heavy rainfall, the result for POD and FAR are less encouraging since none of the three states give good score. Hence it is recommended to use more data by increasing the period of time for more significant result for the future work. In addition, there are also improved WRF model products produced by the MMD that can be used in the future. The WRF model analysis indicate a very promising potential in producing QPF for flood forecasting purposes. These forecast sequences can be used as input to rainfall-runoff hydrological model as an alternative to the available rain-gauge system.

\section{Acknowledgement}

This research has been supported by the Hydrology and Water Resources Division, Drainage and Irrigation Department, Ministry of Natural Resources and Environment Malaysia and GIP Fund 600-IRMI/GIP 5/3 (0005/2016) Research Management Institute (RMI) , UiTM. The authors wish to thank the Faculty of Civil Engineering, Universiti Teknologi MARA (UiTM) for their significant contribution for this study. Appreciation goes to the Drainage (DID) for providing rainfall datasets and Malaysian Meteorological Department (MMD) for providing the WRF model outputs that have been used in this paper. Words of gratitude are also extended to all individuals and organization that have made this study possible.

\section{References}

[1] Nasrollahi, N., Agha Kouchak, A., Li, J., Gao, X., Hsu, K., \& Sorooshian, S. (2012). Assessing the Impacts of Different WRF Precipitation Physics in Hurricane Simulations. Weather and Forecasting, 27(4), 1003-1016.

[2] Skamarock, W. C., Klemp, J. B. J., Dudhia, D. O., Gill, D. M., Barker, M. G., Huang, et al. (2007). A description of the Advanced Research WRF version 3. NCAR Technical Note 47.

[3] Chandrasekar, R. and Balaji, C. (2016). Impact of physics parameterization and 3DVAR data assimilation on prediction of tropical cyclones in the Bay of Bengal region. Nat Hazards, 80, 223-247.

[4] Banks, R.F., Alsina, J.T, Baldasano, J.M., Rocadenbosch, F., Papayannis, A., Solomos, S. \& Tzanis, C.G. (2016). Sensitivity to boundary layer variables to PBL Schemes in the WRF model based on surface meteorological observations, lidar and radiosondes during the HygrA-CD campaign. Atmospheric Research, 176-177, 185-201.

[5] Kala, J., Andrys, J., Lyons, T.J., Foster, I.J. \& Evans, B.J. (2015). Sensitivity of WRF to driving data and physics options on a seasonal time-scale for the southwest of Western Australia. Clim Dyn, 44, 633-659.

[6] Islam, T., Srivastava, P.K., Rico-Ramirez, M.A, Dai, Q., Gupta, M. \& Singh, S.K. (2015). Tracking a tropical cyclone through WRFARW simulation and sensitivity of model physics. Nat Hazards, 76, 1473-1495.

[7] Shrivastava, R., Dash, S.K., Oza, R.B. \& Hegde, M.N. (2015). Evaluation of parameterization schemes in the Weather Research and Forecasting (WRF) model: A case study for the Kaiga nuclear power plant site. Annals of Nuclear Energy, 75, 693-702.

[8] Patel, P. (2015). Flood Simulation using Weather Forecasting and Hydrological Models. Master dissertation, Indian Institute of Remote Sensing, India.

[9] Gochis, D.J., Yu, W. \& Yates, D.N. (2013). The WRF-Hydro model technical description and user's guide Version 1.0. NCAR Tech. Doc.

[10] Skamarock, W. C., Klemp, J. B. J., Dudhia, D. O., Gill, D. M., Barker, M. G., Duda, X.-Y. Huang, W. Wang, and J. G. Powers, (2008). A Description of the Advanced Research WRF Version 3. NCAR Tech. Note NCAR/TN-475+STR, 113.

[11] Chan, N. W. (1997). Increasing Flood Risk in Malaysia: causes and solution. Disaster Prevention and Management: An International Journal, 6(2), 72-86.

[12] Wardah, T., Kamil, A.A., Sahol Hamid,A.B., \& Maisarah,W.W.I. (2011). Quantitative Precipitation Forecast using MM5 and WRF models for Kelantan River Basin. International Journal of Environmental, Chemical, Ecological, Geological and Geophysical Engineering, 5(11), 712-716. 